\title{
POxylation as an alternative stealth coating for biomedical applications
}

Herdis Bludau, ${ }^{1} *$ Anna E. Czapar, ${ }^{2 *}$ Andrzej S. Pitek, ${ }^{3}$ Sourabh Shukla, ${ }^{3}$ Rainer Jordan, ${ }^{1 \#}$ Nicole F. Steinmetz ${ }^{\# 3,4,5,6,7}$

${ }^{1}$ Chair of Macromolecular Chemistry, School of Science, Technische Unversität Dresden, Mommsenstr. 4, 01069 Dresden, Germany

${ }^{2}$ Department of Pathology, ${ }^{3}$ Biomedical Engineering, ${ }^{4}$ Radiology, ${ }^{5}$ Materials Science and Engineering, ${ }^{6}$ Macromolecular Science and Engineering, and ${ }^{7}$ Case Comprehensive Cancer Center, Case Western Reserve University, Cleveland, Ohio 44118, United States

*co-first authors

\#corresponding authors: nicole.steinmetz@case.edu; rainer.jordan@tu-dresden.de

Keywords: polyoxazoline; biomaterial; polymer-conjugates; nanomedicine; tobacco mosaic virus; stealth coatings

\section{$\underline{\text { Abstract }}$}

Polyethylene glycol (PEG) polymers are currently used in a variety of medical formulations to reduce toxicity, minimize immune interactions and improve pharmacokinetics. Despite its widespread use however, the presence of anti-PEG antibodies indicates that this polymer has the potential to be immunogenic and antigenic. Here we present an alternative polymer, poly(2-oxazoline) (POx) for stealth applications, specifically shielding of a proteinaceous nanoparticle from recognition by the immune system. Tobacco mosaic virus (TMV) was used as our testbed due to its potential for use as a nanocarrier for drug delivery and molecular imaging applications.

C 2016. This manuscript version is made available under the Elsevier user license http://www.elsevier.com/open-access/userlicense/1.0/ 


\section{$\underline{\text { Introduction }}$}

The development of nanoparticles for drug delivery is a rapidly expanding area of research with a large number of technologies in the pipeline and a few in clinical applications. Nanocarrier drug delivery systems improve delivery to solid tumors through enhanced bioavailability and increased tumor accumulation. ${ }^{1}$ A variety of nanoparticles are under investigation including polymeric micelles, polymeric capsules, iron oxide and gold nanoparticles, and protein-based particles; each system has distinct advantages and disadvantages relating to manufacturing, toxicity, and biological effects. A common barrier for most nanoparticle formulations is innate immune recognition leading to rapid clearance from circulation and accumulation in non-target organs. Subsequent activation of the adaptive immune system leads to enhanced clearance upon repeat administration due to immune memory. To overcome these barriers, 'stealth' coatings have been developed and implemented to shield nanocarriers from immune surveillance.

Polyethylene glycol (PEG) is the most commonly used polymer stealth coating. PEG is hydrophilic, non-toxic, and reduces protein adhesion, molecular recognition, as well as non-specific cell uptake. These biological characteristics, as well as its commercial availability, including different structural and end-group functionalized varieties, make PEG the current gold standard for stealth applications. ${ }^{2}$ Despite the widespread acceptance of PEG for biomedical applications, anti-PEG antibodies have been reported indicating that PEG has the potential to be immunogenic and antigenic. ${ }^{2}$ Indeed, antiPEG antibodies have been linked to more rapid clearance of PEGylated agents upon 
repeat administration, including PEG-ASNase ${ }^{3}$ and Pegloticase. ${ }^{4,5}$ Moreover, even without prior administration of PEGylated compounds, several patients were reported to experience anaphylaxis due to pre-existing anti-PEG antibodies following administration of a PEG-aptamer formulation. ${ }^{6}$ Among healthy donors without known exposure to PEG, the percent of those who are anti-PEG antibody positive has been reported as high as $25 \% .^{5}$ Interestingly, only $0.2 \%$ occurrence of anti-PEG antibodies was recorded in the early 1980 s. ${ }^{7}$ This increase is likely due to the expanded use of PEG in applications such as cosmetics and food preservatives. ${ }^{2}$ It is clear that a paradigm shift is needed.

Poly(2-oxazoline)s (POx) is a potential alternative class of stealth polymer. POx is a polymer produced by living cationic ring-opening polymerization (LCROP) of 2oxazolines. POx is versatile with a range of available derivatives and end-group and sidechain functionalization. ${ }^{8,9}$ Here we focus specifically on poly(2-methyl-2-oxazoline) (PMeOx); it is more hydrophilic than PEG and thus does not show amphiphilicity. ${ }^{10}$ It has been shown to be highly biocompatible with no cytotoxicity observed at concentrations up to $20 \mathrm{~g} / \mathrm{L}$ in cell culture ${ }^{8,11}$ and up to $2 \mathrm{~g} / \mathrm{kg}$ when administered intravenously to rats ${ }^{12}$ and, to the best of our knowledge, no anti-POx antibodies have been reported. While its use in the past has been limited by the lack of commercial availability, advances in synthesis have reduced total reaction time and improved polydispersity. ${ }^{13,14}$ POXylated proteins, liposomal and micelle-based formulations have been reported. ${ }^{8,15}$ Extensive previous studies showed very good non-biofouling properties of hydrophilic POx coatings that are similar to the PEG gold-standard. ${ }^{16,17}$ Moreover, an enhanced bioavailability as compared to PEGylated formulations are reported. ${ }^{12,15,18,19}$ 
Additionally, POx has been shown to be more stable under physiological conditions. ${ }^{20}$ To gain more insights into the differences of PEGylated and POxylated nanoparticle formulations, we chose to assess PEG vs. PMeOx coatings using the plant viral nanoparticle tobacco mosaic virus (TMV) as the testbed.

Mammalian viruses are already used in gene delivery and oncolytic viral therapy. ${ }^{21,22} \mathrm{We}$ have turned toward plant viruses, because plant viruses are not infectious towards mammals and therefore add a layer of safety. Several plant viruses are currently under investigation for a wide variety of applications including drug delivery, immunotherapy, and imaging. ${ }^{23-30} \mathrm{TMV}$ in particular, is a soft matter, high aspect ratio nanotube measuring 300x18 nm with a $4 \mathrm{~nm}$-wide central channel. The high aspect ratio shape makes it a particularly interesting platform technology: We have shown that its high aspect ratio nature leads to improved blood vessel margination, decreased immune clearance, and improved tumor accumulation compared to spherical nanoparticles. ${ }^{31-34}$ In a recent study we demonstrated enhanced drug delivery of phenanthriplatin, a novel cisplatin derivative, through encapsulation within the interior channel of TMV allowing for improved efficacy in a mouse model of triple negative breast cancer. ${ }^{23}$

Nevertheless, the development of neutralizing antibodies against the protein carrier mounts a potential translational challenge, as has been shown with viral gene delivery approaches. ${ }^{35,36}$ In fact, using intravital microscopy imaging, we recently documented the fates of virus-based nanoparticles after repeat administration. Our studies highlighted the need for a 'stealth' coating, because 'naked' formulations were recognized and cleared by 
the innate and adaptive immune system. ${ }^{37}$ Furthermore, it should be noted that plant viruses are in the food chain. On one hand this is a potentially positive attribute, because our bodies have already experienced plant viruses, on the other hand, prevalence of antiTMV antibodies in healthy volunteers has been reported. ${ }^{38}$ Therefore, to improve bioavailability the next-generation of viral nanoparticles must include stealth surface treatments to avoid immune clearance. Here we evaluate POx, specifically PMeOx, as an alternative to PEG coatings. We compare PEGylated and POxylated TMV formulations and assess their antibody recognition, cell uptake properties, potential cytotoxicity, as well as pharmacokinetics in tissue culture and mice.

\section{$\underline{\text { Experimental }}$}

\section{Synthesis of poly(2-methyl-2-oxazoline) (PMeOx)}

Following a procedure by Volet and Amiel, ${ }^{39}$ azide-functionalized PMeOx was synthesized. Under dry and inert conditions methyl trifluoromethylsulfonate (MeOTf) and 25 or 50 equivalents (PMeOx $2.5 \mathrm{~K}$ and $\mathrm{PMeOx} 5 \mathrm{~K}$ respectively) of 2-methyl2oxazoline $(\mathrm{MeOx})$ were dissolved in $11 \mathrm{~mL}$ acetonitrile. This mixture was stirred at $90^{\circ} \mathrm{C}$ for $2 \mathrm{~h}$ and terminated with 3 equivalents sodium azide for $12 \mathrm{~h}$ at room temperature. After neutralization with an excess of calcium carbonate and centrifugation at $10,000 \times \mathrm{g}$ for $10 \mathrm{~min}$, the clear viscous supernatant was precipitated in ice-cold diethyl ether (approximately 10 times the volume of the polymer solution). The precipitated polymer was dialyzed against Millipore water using a molecular weight cut-off of 1000 Da and lyophilized. The polymers were fully characterized by ${ }^{1} \mathrm{H}-\mathrm{NMR}$ spectroscopy, MALDI- TOF mass spectrometry and gel permeation chromatography (GPC). 
Analytical data of azide-functionalized PMeOx

\begin{tabular}{|c|c|c|c|c|c|}
\hline ID & Structure & $\begin{array}{c}\mathrm{M}_{\mathrm{n}}^{\mathrm{a}} \\
(\mathrm{kg} / \mathrm{mol})\end{array}$ & $\begin{array}{l}\mathrm{M}_{\mathrm{n}}^{\mathrm{b}} \\
(\mathrm{kg} / \mathrm{mol})\end{array}$ & $\begin{array}{l}\mathrm{M}_{\mathrm{n}}^{\mathrm{c}} \\
(\mathrm{kg} / \mathrm{mol})\end{array}$ & $\mathrm{D}^{\mathrm{a}}$ \\
\hline $\begin{array}{l}\text { PMeOx } \\
2.5 \mathrm{~K}\end{array}$ & $\mathrm{~N}$ & 2.4 & 2.2 & 2.2 & 1.13 \\
\hline $\begin{array}{l}\mathrm{PMeOx} \\
5.5 \mathrm{~K}\end{array}$ & N & 5.7 & 4.6 & 5.7 & 1.07 \\
\hline $\begin{array}{l}\text { PEG } \\
5 K^{d}\end{array}$ & & $4.5-5.5$ & & & $<1.10$ \\
\hline
\end{tabular}

(a) as determined by gel permeations chromatography (solvent DMAc at $70^{\circ} \mathrm{C}$; $57 \mathrm{mM} \mathrm{LiBr}$ ) against PMMA calibration.

(b) as determined by MALDI-TOF mass spectrometry with mass signal with highest intensity.

(c) as determined by ${ }^{1} \mathrm{H}-\mathrm{NMR}$ end-group analysis.

(d) commercially available methoxyl polyethyleneglycol azide was used without additional purifications steps; analytical data were provided by NanoCS.

\section{TMV propagation and purification}

TMV was propagated in $N$. benthamiana and purified using previously described procedures. ${ }^{40}$ Purified TMV was stored in $10 \mathrm{mM}$ potassium phosphate $\mathrm{pH} 7.8$ at $4{ }^{\circ} \mathrm{C}$. TMV concentration was determined by UV/visible spectroscopy $\left(\varepsilon_{\mathrm{TMV}}=3.0 \mathrm{~mL} \mathrm{mg}^{-1}\right.$ $\mathrm{cm}^{-1}$ at $\left.260 \mathrm{~nm}\right)$.

\section{Surface modification and characterization of TMV}

The following protocol was modified from the established methods. ${ }^{24,40}$ First an alkyne group was introduced at the exterior tyrosine group through an electrophilic substitution reaction with in situ formed diazonium salt. Diazonium salt was formed by mixing $75 \mu \mathrm{L}$ $0.68 \mathrm{M}$ 3-ethynyl aniline with $25 \mu \mathrm{L} 3.0 \mathrm{M}$ sodium nitrite in $400 \mu \mathrm{L} 0.3 \mathrm{M}$ p-toluene 
sulfonic acid monohydrate aqueous solution. This solution was added to TMV $(2 \mathrm{mg} / \mathrm{mL})$ in $10 \mathrm{mM}$ borate buffer $\mathrm{pH} 8.8$ on ice at an excess of 35 equivalents per coat protein. Following addition of the alkyne group, terminal alkynes were modified by azideterminated PEG or PMeOx polymers and azide functionalized Cy5 dye through $\mathrm{CuAAC}$. Particles were first reacted with 50 equivalents per coat protein of polymer for two hours followed by one hour of reaction with 10 equivalents of Cy5. Reactions were performed in $10 \mathrm{mM}$ potassium phosphate buffer at $\mathrm{pH} 7.8$ with TMV $(2 \mathrm{mg} / \mathrm{mL})$, copper sulfate (2 $\mathrm{mM})$, sodium ascorbate $(1 \mathrm{mM})$, and aminoguanidine $(1 \mathrm{mM})$. CuAAC reaction was stopped by the addition of $5 \mathrm{mM}$ ethylenediaminetetraacetic acid. Following each step, reaction mix was purified using ultracentrifugation at 160,000 $x \mathrm{~g}(42,000 \mathrm{rpm}$ when using Beckman Coulter Type model 50.2Ti) for 3 hours over a $40 \%$ sucrose cushion.

SDS-PAGE was used to determine the number of polymer molecules per TMV particle. $15 \mu \mathrm{g}$ of denatured protein samples were loaded and run on $4-12 \%$ NuPage gels (Life Technologies) in MOPS buffer at $200 \mathrm{~V}$ for $45 \mathrm{~min}$. Protein bands were visualized under white light following staining with Coomassie blue $(0.25 \% \mathrm{w} / \mathrm{v})$.

TMV particles $(20 \mu \mathrm{L}$ at $0.1 \mathrm{mg} / \mathrm{mL})$ were negatively stained with $2 \%(\mathrm{w} / \mathrm{v})$ uranyl acetate for 5 min on carbon coated copper grids (Ted Pella), blotted, rinsed with $\mathrm{diH}_{2} \mathrm{O}$, and allowed to dry completely. Samples were imaged using a Zeiss Libra 200FE transmission electron microscope at $200 \mathrm{kV}$. 
For MALDI-TOF analysis native and modified TMV particles at a concentration of $12 \mathrm{mg} / \mathrm{mL}$ were denatured in $6 \mathrm{M}$ guanidine chloride aqueous solution for $5 \mathrm{~min}$ at room temperature. Denatured samples were spotted onto a MTP 384 steel target and using C4 zip tips (Millipore) for concentration and desalting. MALDI-TOF MS analysis was performed using a Bruker Ultra-Flex I TOF/TOF mass spectrometer.

\section{Antibody recognition of TMV with PEG and PMeOx surface modifications}

Recognition of stealth modified TMV particles by TMV-specific antibodies was tested using a commercially available TMV ELISA kit (Agdia). $10 \mu \mathrm{g}$ of particle was added to each well in triplicate and supplier instructions were followed as written. Absorbance was read at $405 \mathrm{~nm}$ using a Tecan microplate reader.

Recognition of particles by anti-PEG antibodies was tested using a dot blot assay. Nitrocellulose membrane was soaked in potassium phosphate buffer for 5 min and kept hydrated while $3 \mu \mathrm{L}$ of $1 \mathrm{mg} / \mathrm{mL}$ samples were spotted onto the membrane in triplicate. After 5 minutes to allow the proteins to adhere to the membrane the membrane was blocked in 5\% (w/v) milk in Tris-buffered saline (TBS) overnight at $4^{\circ} \mathrm{C}$. Following blocking, the membrane was incubated for $1 \mathrm{~h}$ with primary rabbit anti-PEG antibody (Abcam) at 1:100 $(0.5 \mathrm{mg} / \mathrm{mL})$ in $5 \%(\mathrm{w} / \mathrm{v})$ milk/TBS. The membrane was then incubated with a secondary goat anti-rabbit-alkaline phosphatase antibody (Sigma Aldrich) $(2 \mathrm{mg} / \mathrm{mL})$ for $1 \mathrm{~h}$ at room temperature. In between each incubation step, the membrane was washed four times with TBS. 5-bromo-4-chloro-3-indolyl phosphate 
(BCIP, Thermo Scientific) was added to develop and the dot blot was visualized under white light and spot density was determined using ImageJ (https://imagej.nih.gov/ij/).

\section{Cell uptake of TMV particles}

RAW264.7 cells were grown to confluency and collected using Hank's enzyme free cell dissociation buffer (Fisher). Cells were counted and added to 96-well v-bottom plates (500,000 cells per well) and incubated with 1 x $10^{6}$ TMV particles per cell for either 3 or 6 h. Following incubation, cells were washed three times with FACS buffer ( $1 \mathrm{mM}$ EDTA, $25 \mathrm{mM}$ HEPES, $1 \%(\mathrm{v} / \mathrm{v}) \mathrm{FBS}$ in PBS) and fixed in 2\% (v/v) paraformaldehyde (Electron Microscopy Science) buffer for 10 minutes at room temperature. Following fixing, cells were washed twice and resuspended in $200 \mu \mathrm{L}$ FACS buffer. Cells were analyzed using a BD LSR II Flow Cytometer. 10,000 gated events were recorded for sample and data was analyzed using FlowJo 8.6.3 software. Samples were run in triplicate and testing was performed three times.

\section{Cell viability of POxylated TMV}

RAW264.7 cells were seeded (2,000 cells in $200 \mu \mathrm{L}$ complete DMEM) in a sterile, tissue-culture treated 96-well plate and allowed to recover overnight. After $24 \mathrm{~h}$, cells were washed, and particles diluted in complete growth media were added to the cells in concentrations ranging from $0.5 \mathrm{mg} / \mathrm{mL}$ to $0.05 \mathrm{mg} / \mathrm{mL}$. The maximum concentration corresponds to an in vivo dosing of $500 \mathrm{mg} / \mathrm{kg}$, which is over an order of magnitude higher than the dosing of most viral nanoparticles. Cells were maintained at $37^{\circ} \mathrm{C}$ and 
$5 \% \mathrm{CO}_{2}$. After $24 \mathrm{~h}$, media was removed, cells were washed with phosphate buffered saline, and fresh media was added. Cell viability was determined using an MTT proliferation assay. The assay was carried out according to manufacturer instructions (ATCC).

\section{Pharmacokinetics of TMV with PEG and PMeOx surface modifications in Balb/C mice}

All experiments were carried out in accordance with Case Western Reserve University Institutional Animal Care and Use Committee. Pharmacokinetics was determined in healthy male Balb/C mice (Charles River, $\mathrm{n}=3$ ). TMV-PEG $5 \mathrm{~K}$ and TMV-PMeOx 5K was injected via tail vein at a dose of $200 \mu \mathrm{g}$ per mouse in $100 \mu \mathrm{L}$ PBS. Blood was collected at 10, 30, 60, 120, and 360 min post-injection via a retro-orbital bleed. Serum was separated from red blood cells via centrifugation at 2,000 $x \mathrm{~g}$ for $10 \mathrm{~min}$. Fluorescence was read using a Tecan microplate reader $\left(\lambda_{\mathrm{Ex}}=649 \mathrm{~nm}, \lambda_{\mathrm{Em}}=666 \mathrm{~nm}\right)$. Measured fluorescence was correlated to a standard curve normalized to each particle formulation to determine the particle concentration at each time point. Percent-injected dose was determined based on calculated particle concentration from each time point. Data was analyzed using Prism Graphpad. Two-phase exponential decay was chosen, because this model reflects pharmacokinetic profiles of materials cleared by a combination of kidney clearance and liver metabolism; this route of clearance has been demonstrated for other viral nanoparticles. ${ }^{41}$ 


\section{$\underline{\text { Results and Discussion }}$}

\section{Synthesis and characterization of surface coated TMV particles}

TMV was purified following infection in $N$. benthamiana plants using previously established protocols. ${ }^{24} \mathrm{PMeOx}$ and PEG polymer coatings were applied to TMV, and cellular uptake, antibody recognition, and pharmacokinetics of the TMV-polymer conjugates were evaluated using tissue culture and a mouse model. Chemical conjugation was achieved by first modifying TMV's exterior tyrosine residue (TYR139) to an alkyne group through diazonium coupling. Following diazonium coupling, either PEG, purchased from Nanocs, with a molar mass of $5 \mathrm{kDa}$ (PEG 5K), PMeOx with a molar mass of $2.6 \mathrm{kDa}(\mathrm{PMeOx} 2.5 \mathrm{~K})$, or $\mathrm{PMeOx}$ with a molar mass of $5.1 \mathrm{kDa}(\mathrm{PMeOx} 5 \mathrm{~K}$; all polymers were functionalized with a terminal azide linker) were conjugated using $\mathrm{Cu}(\mathrm{I})$-catalyzed azide alkyne cycloaddition (CuAAC) (Fig. 1). For cellular uptake and pharmacokinetics experiments TMV particles were also functionalized with Cy5 azide dye for tracking (see Materials and Methods section for detailed experimental procedures). Particles were purified by ultracentrifugation and final products were characterized by TEM, UV/visible spectroscopy, SDS-PAGE, and MALDI-TOF mass spectrometry (Fig. 2).
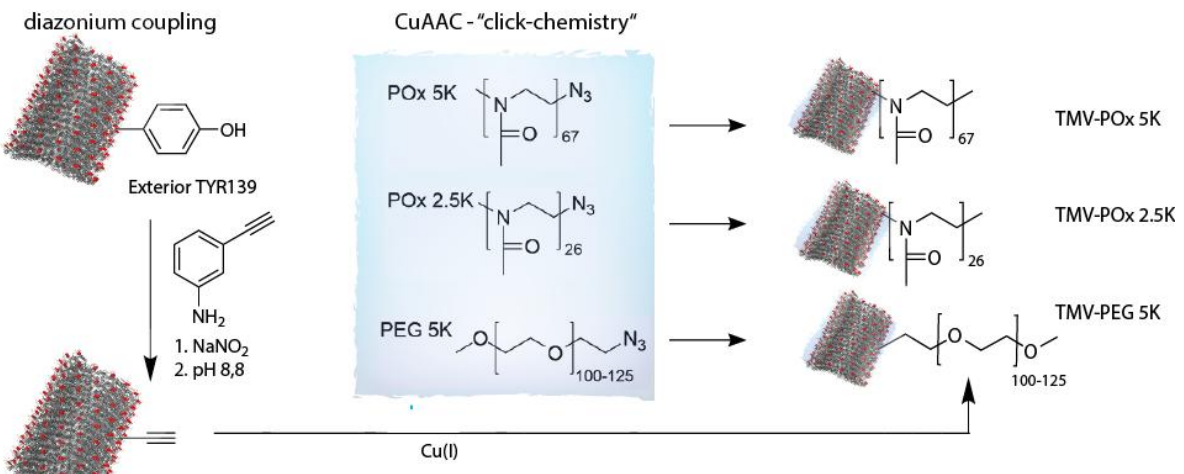


\section{Figure 1. Schematic illustrating polymer conjugation.}

TEM analysis showed that the TMV particles remained intact following modification (Fig. 2A). UV/Vis spectroscopy was used to determine the number of Cy5 dyes per TMV particle using the Beer-Lambert law. TMV-specific extinction coefficient is $\varepsilon_{\mathrm{TMV}}=3.0$ $\mathrm{mL} \mathrm{mg}^{-1} \mathrm{~cm}^{-1}$ at $260 \mathrm{~nm}$ with a TMV molar mass of $3.94 \times 10^{7} \mathrm{~g} / \mathrm{mol}$; the extinction coefficient for Cy5 is $\varepsilon_{\mathrm{Cy} 5}=271,000 \mathrm{M}^{-1} \mathrm{~cm}^{-1}$. The density of dye-labeling for the three surface-coated formulations was as follows: 79 dyes per TMV-PEG5K, 86 dyes per TMV-POx 5K, and 70 dyes per TMV-POx 2.5K. The degree of dye-labeling between the formulations thus is closely matched with all samples within $10 \%$ of the average dye content of 78 .

SDS-PAGE and lane density analysis using ImageJ software were used to determine the percentage of TMV coat proteins modified by the polymer (Fig. 2B). Higher molar mass bands indicated successful conjugation of the polymer. It was determined that $12-13 \%$, $29-39 \%$, and $27-37 \%$ of coat proteins were modified when TMV was reacted with PEG 5K, $\mathrm{PMeOx} 5 \mathrm{~K}$, and $\mathrm{PMeOx} 2.5 \mathrm{~K}$ respectively. Surface modification was further confirmed by the mass shift observed through MALDI-TOF-MS analysis (Fig. 2C). Dyelabeled particles were used for pharmacokinetic and flow cytometry studies while unlabeled particles were used for antibody recognition and cell viability studies.

The Flory dimension $\left(\mathrm{R}_{\mathrm{F}}\right)$ of each polymer chain was calculated and used to estimate the total surface coverage for each polymer type. 
For linear polymers: $\mathrm{R}_{\mathrm{F}}=\mathrm{an}^{3 / 5}$

Where $\mathrm{a}=$ length of one monomer $(0.35 \mathrm{~nm}$ for PEG and $0.32 \mathrm{~nm}$ for PMeOx $)$ and $\mathrm{n}=$ number of monomers per chain. ${ }^{42,43}$ Based on this equation, the $\mathrm{R}_{\mathrm{F}}$ for PEG $5 \mathrm{~K}, \mathrm{PMeOx}$ 5K, and PMeOx 2.5K was calculated to be $5.87 \mathrm{~nm}, 3.99 \mathrm{~nm}$, and $2.26 \mathrm{~nm}$ respectively. The total surface area of TMV is $A_{\mathrm{TMV}}=16,964 \mathrm{~nm}^{2}$ and it is made up of 2,130 identical coat proteins. A statistically random and homogenous distribution of polymer modification on the TMV surface was assumed. Distances between modified coat proteins were calculated based on the total surface area of the TMV particle and the number of coat proteins modified and were found to be $7.82 \mathrm{~nm}, 5.24 \mathrm{~nm}$, and $5.43 \mathrm{~nm}$ for PEG 5K, PMeOx 5K, and PMeOx 2.5K respectively. For PEG 5K and PMeOx 5K the $2 \mathrm{R}_{\mathrm{f}}$ is greater by $\sim 35 \%$, according to the deGennes scaling laws we expect a mixed brush-mushroom conformation achieving 100\% surface coating for these polymers. Because $\mathrm{D}<2 \mathrm{R}_{\mathrm{f}}$ for $\mathrm{PMeOx} 2.5 \mathrm{~K}$, it likely exists in the mushroom conformation.

It was interesting to note that POxylation yielded a higher degree of coat protein modification compared to PEGylation. While $30 \%$ of coat proteins were modified with POx, independent of the polymer molar mass, PEGylation only yielded $15 \%$ modified coat proteins. This difference in attachment was observed even following a number of different reaction conditions (during the course of reaction optimization) and when two independent researchers performed the conjugation reactions. It is not completely clear why more polymer attachment was obtained with POx. One possible explanation may be 
differences in the degree of hydration, because one study indicates that PEG has a higher degree of hydration than POx. ${ }^{12}$ The increased water content may relate to lower degree of PEG vs. POx conjugation to TMV. Other reasons may be differences in polymer chain conformations or in the degrees of functionalization of the commercially obtained PEG vs. the synthesized POx. This improvement in POx surface coating compared to PEG could be another valuable advantage of this polymer as it would allow for increased surface coating and/or functionalization. 

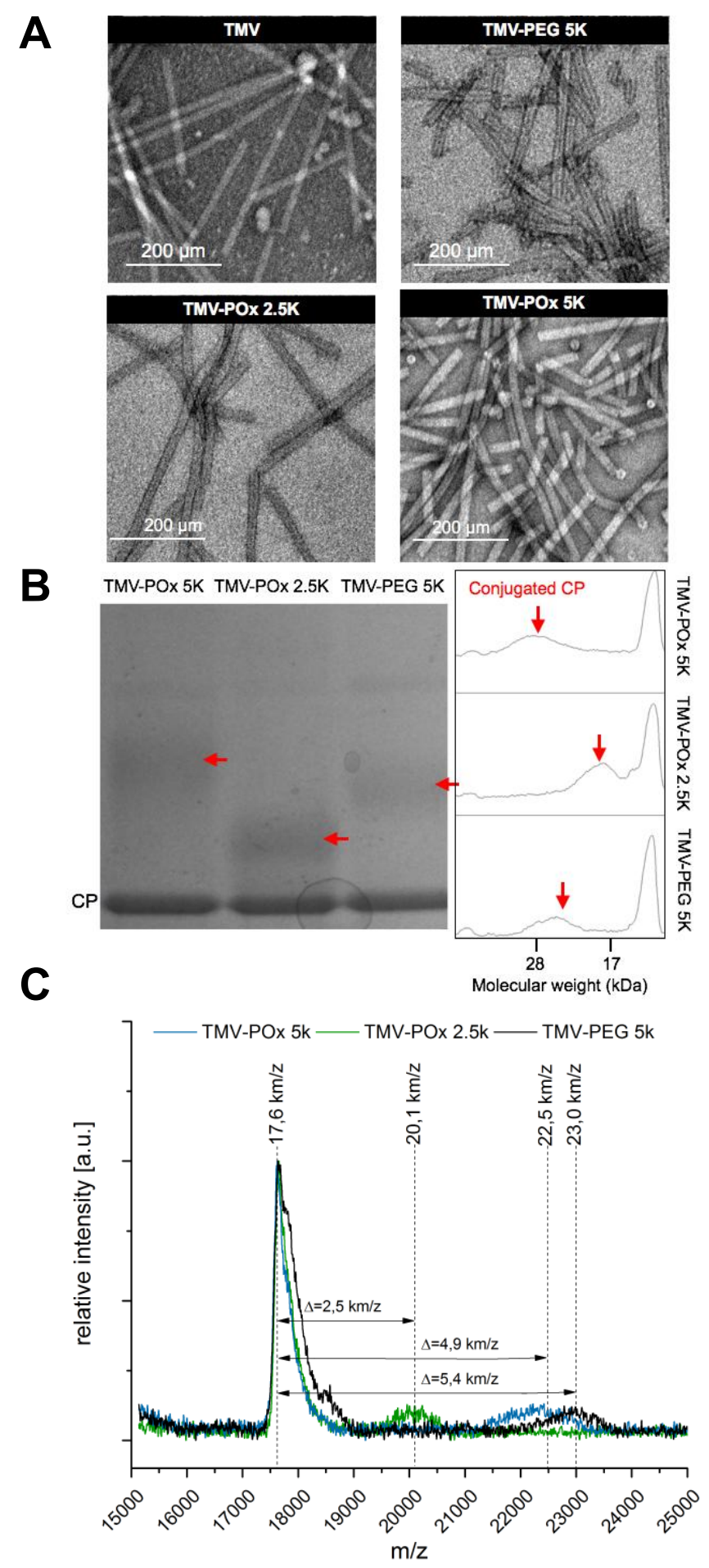

Figure 2. Characterization of surface modified TMV particles. A. Negatively stained TEM images of particles following surface modification. B. SDS PAGE following staining with Coomassie blue and band densitometry as determined by ImageJ. Size measurements determined using SeeBlue Plus2 protein ladder C. MALDI-TOF mass spectrum of modified particles. 


\section{Antibody recognition of surface modified TMV particles}

As with other viruses and nanoparticle formulations, TMV is recognized by the immune system. Innate immune recognition and immune memory can lead to enhanced clearance after repeat administration. In particularly, clearance by neutralizing antibodies has been a considerable challenge for protein and viral therapies. ${ }^{44,45}$ Stealth coatings with polymers have been shown to reduce antibody recognition and clearance of (virus-based) nanoparticles. ${ }^{29}$ Both PEG and anti-TMV antibodies have been detected in human subjects, likely due to their presence in cosmetics (PEG), ${ }^{2}$ and food chain as well as tobacco products (TMV). ${ }^{38}$ Therefore it is critical to assess whether PEG or POx coatings are efficient to overcome antibody recognition.

To determine how the different surface coatings affect immune recognition, each particle formulation was tested to determine anti-TMV antibody recognition using a commercially available ELISA assay (Agdia). While antibody recognition of the PEGylated TMV was only slightly decreased compared to 'naked' TMV, both POx 5K and POx $2.5 \mathrm{~K}$ significantly reduced the antibody recognition of TMV. The improved ability of POx to shield TMV from antibody recognition may be due to the higher concentration of modified coat proteins on each particle (Fig. 3).

Additionally, cross-recognition of the POx coating by anti-PEG antibodies was determined using dot blot assay. Reactivity against anti-PEG antibodies was determined based on density analysis after secondary staining using ImageJ densitometry analysis. 
As expected, particles with POx coatings were not recognized by anti-PEG antibodies indicating that POx is a valuable alternative to patients that have pre-existing anti-PEG antibodies and there is not cross-reactivity between the polymers. Overall the data suggests that the addition of POx has the potential to significantly reduce immune clearance following repeat administrations through reduction of specific antibody recognition.

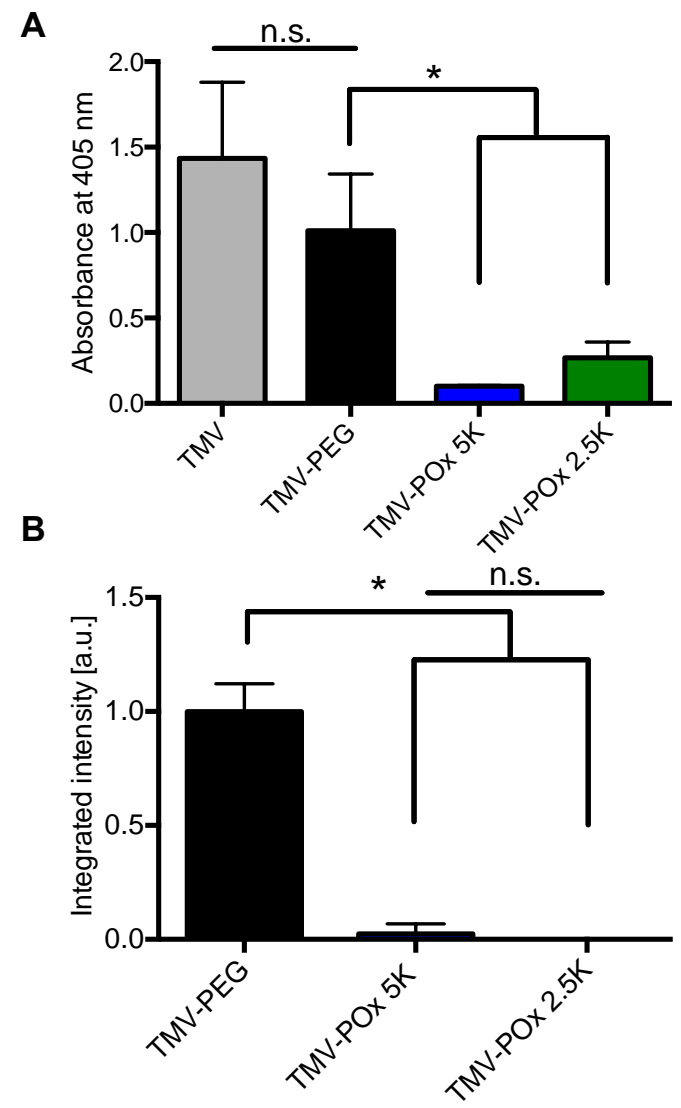

Figure 3. Antibody recognition of native and stealth coated TMV. (A) Recognition of particles by anti-TMV antibody as determined by sandwich ELISA *p<0.01 (B) Recognition of particles by anti-PEG antibodies as determined using dot blot assay *p<0.001. p-values were calculated in Excel using a two-tailed, type 2 t-test. 


\section{Cellular uptake and viability}

Clearance by mononuclear phagocyte cells such as macrophages is a barrier to many nanoparticle systems. Therefore, we evaluated uptake of native vs. polymer-coated TMV in macrophages using cell line RAW264.7 and flow cytometry. Cells were incubated with $1 \times 10^{6}$ fluorescently labeled particles (TMV-PEG, TMV-POx 5K and TMV-POx 2.5K) per cell for 3 or 6 hours (Fig. 4). Uptake studies indicate that POx coatings significantly reduce cell uptake compared to PEGylation of TMV, with higher molecular weight coatings resulting in lowest cell uptake (POx $5 \mathrm{~K}<\mathrm{POx} 2.5 \mathrm{~K}<\mathrm{PEG}$ ).

While PEGylated formulations reached maximum uptake ( 80\%) within $3 \mathrm{~h}$, POxylated formulations had decreased uptake rates; even after $6 \mathrm{~h}$ yielding only $40 \%$ and $60 \%$ for TMV-POx 5K and TMV-POx 2.5K, respectively. Thus data indicate that POx coatings prevent nanoparticle-cell interactions more efficiently as compared to traditional PEG coatings. This is likely due to the higher polymer grafting density of POxylated particles that reduce cellular recognition and protein adhesion. Higher polymer grafting density has also been associated with a reduction in protein adhesion ${ }^{46}$ protein attachment to nanoparticles has been shown to increase cellular uptake. ${ }^{47}$ Moreover, it has been reported that other POx coated nanoparticle systems (polyplexes) show very low plasma protein binding. ${ }^{48}$

In addition to cellular uptake, cellular viability in the presence of surface-modified TMV was tested using MTT assay. In the presence of concentrations of TMV up to 0.5 $\mathrm{mg} / \mathrm{mL}$, no reduction in cellular proliferation or viability was observed with any of the 
tested surface coatings. This concentration correlates to an in vivo dosing of $500 \mathrm{mg} / \mathrm{kg}$ and is an excess of over $3.8 \times 10^{12}$ particles per cell. This further confirms the previously reported non-toxic nature of both, TMV and PMeOx. ${ }^{8,24}$

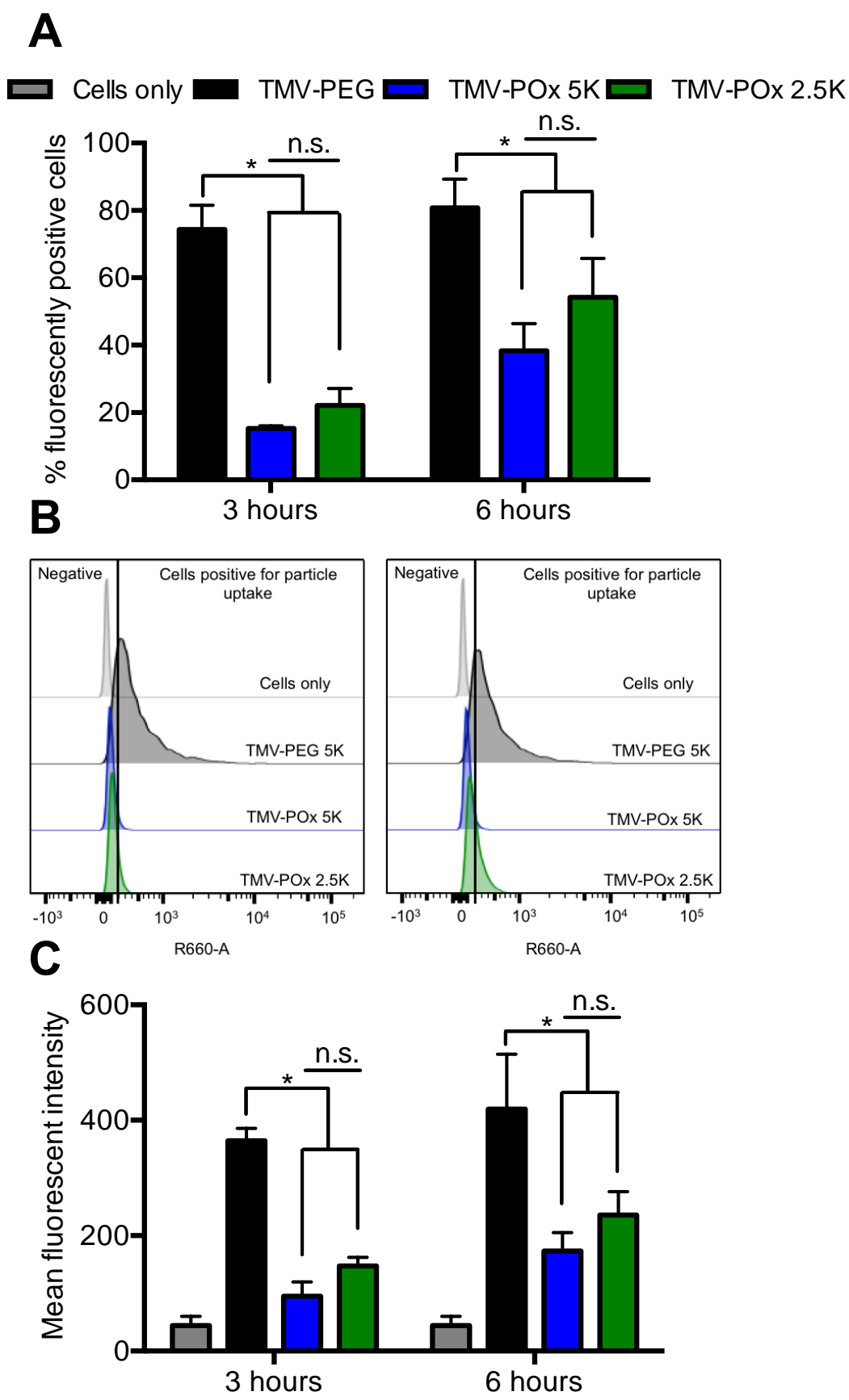

Figure 4. RAW 264.7 macrophage cell line uptake of stealth coated TMV as determined by flow cytometry. (A) Percent of cells determined to be positive for 
fluorescently tagged particles (B) Histogram of Cy5 signal for surface modified TMV in RAW264.7 cells (C) Mean fluorescent intensity of cells incubated with different nanoparticle formulations ${ }^{*} p<0.05$. p-values were calculated in Excel using a two-tailed, type 2 t-test.

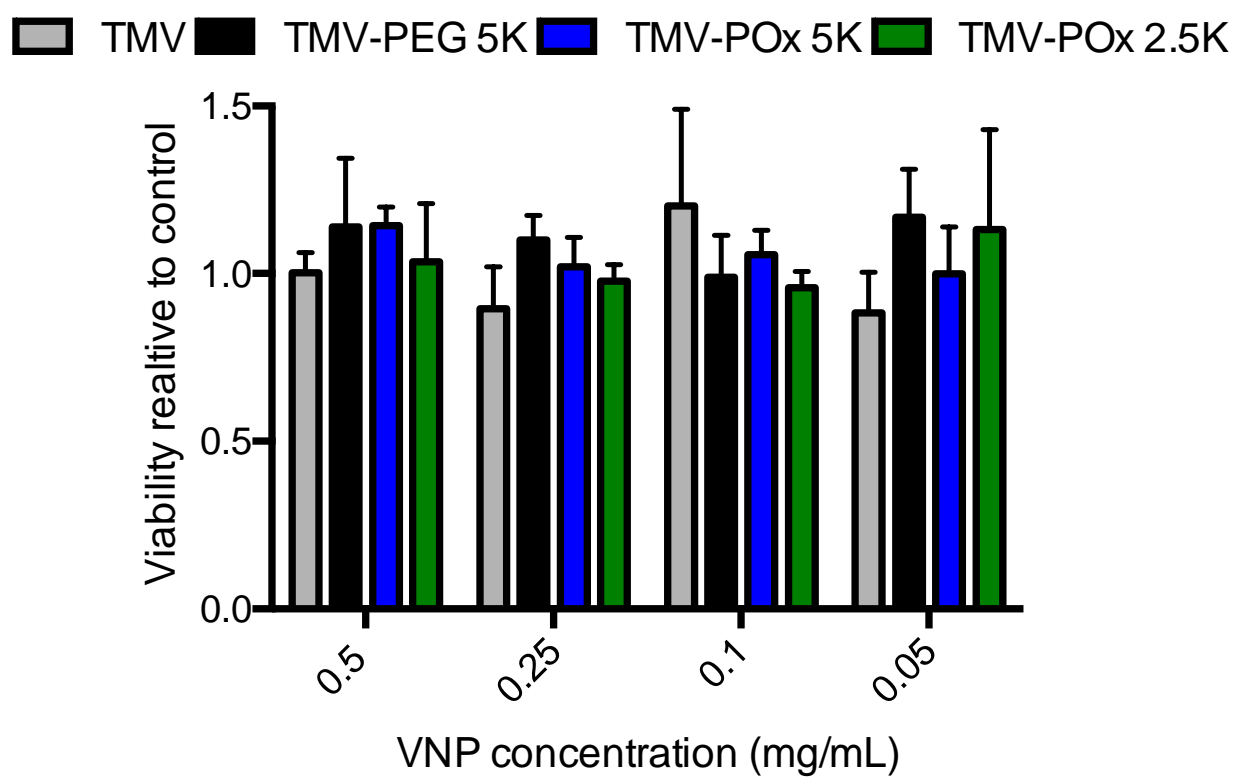

Figure 5. RAW 264.7 macrophage cell line viability following $24 \mathrm{~h}$ of treatment with native and polymer-coated TMV particles. Particles were administered at concentrations up to $0.5 \mathrm{mg} / \mathrm{mL}$, corresponding to a $500 \mathrm{mg} / \mathrm{kg}$ in vivo dose. No statistical difference (as calculated by type two, two-tailed t-test in Excel) in cell proliferation was observed.

\section{Pharmacokinetics of surface modified TMV}

Next, we set out to evaluate the pharmacokinetics of PEGylated and POxylated TMV.

As the longer POx polymer was shown to be more effective in reducing antibody recognition and immune cell uptake, formulations coated with $\mathrm{POx} 5 \mathrm{~K}$ were chosen for these experiments. We previously reported that 'naked' TMV is cleared rapidly from circulation with a half-life of only $3.5 \mathrm{~min} .{ }^{24}$ Data were fitted for one-phase decay or twophase decay using GraphPad Prism to determine the plasma half-life. Fitting indicates that polymer-coated TMV formulations follow a two-phase decay, characterized by a 
faster initial clearance rate and a slower clearance for the remaining time (Figure 6). Rsquared values for TMV-PEG and TMV-POx are 0.9524 and 0.9926 respectively. While data indicate more accelerated initial clearance of the PEGylated vs. POx-coated TMV, the slow decay half-lives indicate similar plasma residence of the PEGylated vs.

POxylated TMV. Overall, the two-phase pharmacokinetic profiles of TMV-POx is in good agreement with the clearance rates of PEGylated TMV and other high aspect ratio plant viral nanoparticles, and reflect the combined renal and mononuclear phagocyte system (MPS) clearance. ${ }^{41}$

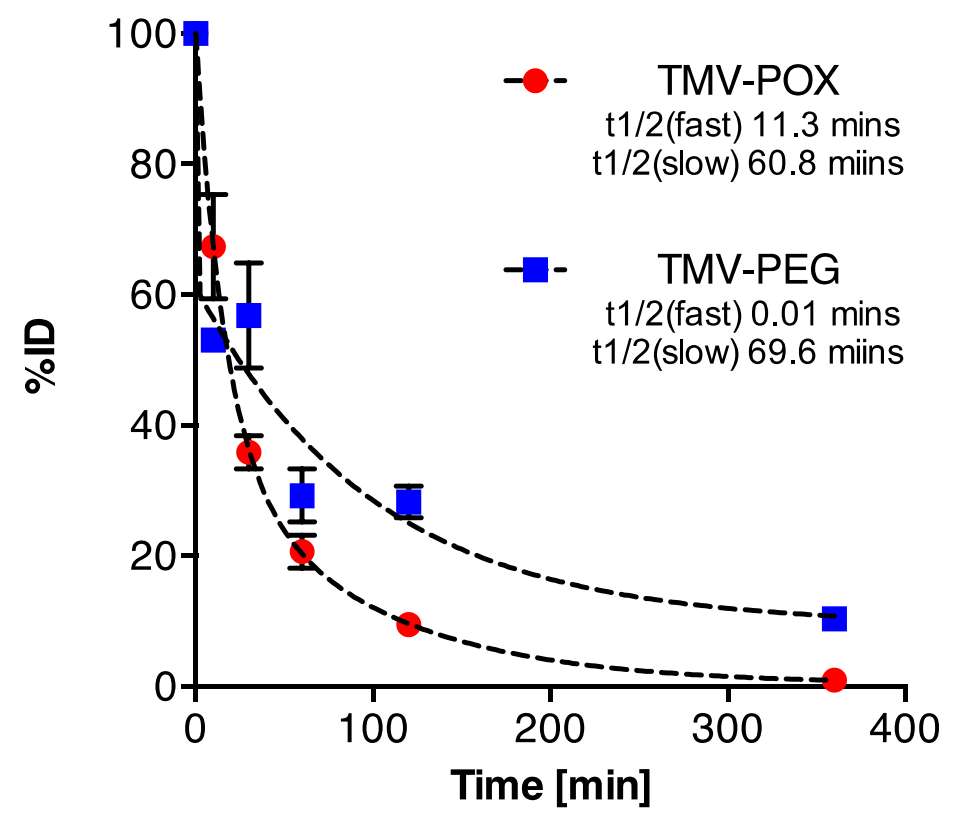

Figure 6. Pharmacokinetics of coated TMV following intravenous injection. Halflives were calculated using Prism 6 calculated assuming a two phase, exponential decay. 


\section{Conclusions}

Here we have described the use of hydrophilic POx (poly(2-methyl-2-oxazoline, PMeOx) as an alternative stealth coating for a viral nanoparticle delivery system. Data indicate that PMeOx has improved screening capability when compared to PEG. As the prevalence of pre-existing antibodies to PEG increase, it is vitally important to explore other polymers that can be used to achieve reduced immune recognition through similar chemistry. POx chemistry as discussed in this paper provides such a suitable alternative strategy. Beyond the "stealthing" of viral nanocarriers, a better understanding of the immune interactions of POx and POx-protein conjugates will be of importance to biopharmaceuticals.

\section{$\underline{\text { Acknowledgements }}$}

This work was supported in part by grants from the Deutscher Akademischer Austauschdienst (IPID4all to R.J. and N.F.S.), National Science Foundation (CHE 1306447 to N.F.S.), National Institutes of Health R03-EB020602 and the German initiative of excellence through the Dresden Initiative of Bioactive Interfaces \& Materials (DIB). A.E.C. was supported in part by NIH grants T32 GM007250 and TL1 TR000441. M. Sc. Jannick Rüb, M. Sc. Jonas Nawroth and Dr. Amy M. Wen are acknowledged for their help with MALDI-TOF. We thank Case Western Reserve University Farm for support in scaled-up molecular farming. 


\section{References}

1 J. B. Hall, M. A. Dobrovolskaia, A. K. Patri and S. E. McNeil, Nanomedicine, 2014, $1-19$.

2 R. P. Garay, R. El-Gewely, J. K. Armstrong, G. Garratty and P. Richette, Expert Opinion on Drug Delivery, 2012, 9, 1319-1323.

3 J. K. Armstrong, G. Hempel, S. Koling, L. S. Chan, T. Fisher, H. J. Meiselman and G. Garratty, Cancer, 2007, 110, 103-111.

4 M. A. Becker, H. S. B. Baraf, R. A. Yood, A. Dillon, J. Vázquez-Mellado, F. D. Ottery, D. Khanna and J. S. Sundy, Ann Rheum Dis, 2013, 72, 1469-1474.

5 J. K. ArmstrongJona, in PEGylated Protein Drugs Basic Science and Clinical Applications, ed. F. M. Veronese, 2009, pp. 147-169.

6 N. J. Ganson, T. J. Povsic, B. A. Sullenger, J. H. Alexander, S. L. Zelenkofske, J. M. Sailstad, C. P. Rusconi and M. S. Hershfield, The Journal of Allergy and Clinical Immunology, 2016, 137, 1610-1613.e7.

7 A. W. Richter and E. Akerblom, Int Arch Allergy Appl Immunol, 1984, 74, 36-39.

8 R. Luxenhofer, Y. Han, A. Schulz, J. Tong, Z. He, A. V. Kabanov and R. Jordan, Macromol. Rapid Commun., 2012, 33, 1613-1631.

9 F. Manzenrieder, R. Luxenhofer, M. Retzlaff, R. Jordan and M. G. Finn, Angew. Chem. Int. Ed., 2011, 50, 2601-2605.

10 M. B. Foreman, J. P. Coffman, M. J. Murcia, S. Cesana, R. Jordan, G. S. Smith and C. A. Naumann, Langmuir, 2003, 19, 326-332.

11 R. Luxenhofer, A. Schulz, C. Roques, S. Li, T. K. Bronich, E. V. Batrakova, R. Jordan and A. V. Kabanov, Biomaterials, 2010, 31, 4972-4979.

12 T. X. Viegas, M. D. Bentley, J. M. Harris, Z. Fang, K. Yoon, B. Dizman, R. Weimer, A. Mero, G. Pasut and F. M. Veronese, Bioconjugate Chem., 2011, 22, 976-986.

13 F. Wiesbrock, R. Hoogenboom, M. A. M. Leenen, M. A. R. Meier and U. S. Schubert, Macromolecules, 2005, 38, 5025-5034.

14 F. Wiesbrock, R. Hoogenboom, C. H. Abeln and U. S. Schubert, Macromol. Rapid Commun., 2004, 25, 1895-1899.

15 J. Tong, X. Yi, R. Luxenhofer, W. A. Banks, R. Jordan, M. C. Zimmerman and A. V. Kabanov, Mol. Pharmaceutics, 2013, 10, 360-377.

16 R. Konradi, B. Pidhatika, A. Mühlebach and M. Textor, Langmuir, 2008, 24, 613616.

17 N. Zhang, T. Pompe, I. Amin, R. Luxenhofer, C. Werner and R. Jordan, Macromol. Biosci., 2012, 12, 926-936.

18 S. Zalipsky, C. B. Hansen, J. M. Oaks and T. M. Allen, J. Pharm. Sci., 1996, 85, 133-137.

19 M. C. Woodle, C. M. Engbers and S. Zalipsky, Bioconjugate Chem., 1994, 5, 493496.

20 B. Pidhatika, M. Rodenstein, Y. Chen, E. Rakhmatullina, A. Mühlebach, C. Acikgöz, M. Textor and R. Konradi, Biointerphases, 2012, 7, 1-15.

21 N. Woller, E. Gurlevik, C.-I. Ureche, A. Schumacher and F. Kühnel, Frontiers in Oncology, 2014, 1-13.

22 M. Giacca and S. Zacchigna, Journal of Controlled Release, 2012, 161, 377-388. 
23 A. E. Czapar, Y.-R. Zheng, I. A. Riddell, S. Shukla, S. G. Awuah, S. J. Lippard and N. F. Steinmetz, ACS Nano, 2016, acsnano.5b07360-8.

24 M. A. Bruckman, L. N. Randolph, A. VanMeter, S. Hern, A. J. Shoffstall, R. E. Taurog and N. F. Steinmetz, Virology, 2014, 449, 163-173.

25 M. A. Bruckman, K. Jiang, E. J. Simpson, L. N. Randolph, L. G. Luyt, X. Yu and N. F. Steinmetz, Nano Lett., 2014, 14, 1551-1558.

26 A. M. Wen, S. Shukla, P. Saxena, A. A. A. Aljabali, I. Yildiz, S. Dey, J. E. Mealy, A. C. Yang, D. J. Evans, G. P. Lomonossoff and N. F. Steinmetz, ..., 2012.

27 A. M.-C. Wen, N. Le, X. Zhou, N. F. Steinmetz and D. Popkin, ACS Biomater. Sci. Eng., 2015, 151020085052002-5.

28 A. M. Wen, K. L. Lee, P. Cao, K. Pangilinan, B. L. Carpenter, P. Lam, F. A. Veliz, R. A. Ghiladi, R. C. Advincula and N. F. Steinmetz, Bioconjugate Chem., 2016, acs.bioconjchem.6b00075-9.

29 K. L. Lee, S. Shukla, M. Wu, N. R. Ayat, C. E. El Sanadi, A. M. Wen, J. F. Edelbrock, J. K. Pokorski, U. Commandeur, G. R. Dubyak and N. F. Steinmetz, Acta Biomaterialia, 2015, 19, 166-179.

30 P. H. Lizotte, A. M. Wen, M. R. Sheen, J. Fields, P. Rojanasopondist, N. F. Steinmetz and S. Fiering, Nature Nanotech, 2015, advance online publication SP EP.

31 V. P. Chauhan, Z. Popović, O. Chen, J. Cui, D. Fukumura, M. G. Bawendi and R. K. Jain, Angew. Chem. Int. Ed., 2011, 50, 11417-11420.

32 S. Shukla, A. M. Wen, N. R. Ayat, U. Commandeur, R. Gopalkrishnan, A.-M. Broome, K. W. Lozada, R. A. Keri and N. F. Steinmetz, Nanomedicine, 2014, 9, 221-235.

33 S. Shukla, A. L. Ablack, A. M. Wen, K. L. Lee, J. D. Lewis and N. F. Steinmetz, Molecular ..., 2012.

34 S. Shukla, F. J. Eber, A. S. Nagarajan, N. A. DiFranco, N. Schmidt, A. M. Wen, S. Eiben, R. M. Twyman, C. Wege and N. F. Steinmetz, Adv. Healthcare Mater., 2015, 4, 874-882.

35 M. A. Kotterman, T. W. Chalberg and D. V. Schaffer, Annu. Rev. Biomed. Eng., 2015, 17, 63-89.

36 R. Waehler, S. J. Russell and D. T. Curiel, Nat Rev Genet, 2007, 8, 573-587.

37 S. Shukla, R. D. Dorand, J. T. Myers, S. E. Woods, N. M. Gulati, P. L. Stewart, U. Commandeur, A. Y. Huang and N. F. Steinmetz, ACS Biomater. Sci. Eng., 2016, 2 , 829-837.

38 R. Liu, R. A. Vaishnav, A. M. Roberts and R. P. Friedland, PLoS ONE, 2013, 8, e60621-7.

39 G. Volet, T.-X. Lav, J. Babinot and C. Amiel, Macromol. Chem. Phys., 2010, 212, $118-124$.

40 M. A. Bruckman and N. F. Steinmetz, in Characterization of Nanoparticles Intended for Drug Delivery, ed. S. E. McNeil, Humana Press, Totowa, NJ, 2013, vol. 1108, pp. 173-185.

41 K. L. Lee, S. Shukla, M. Wu, N. R. Ayat, C. E. El Sanadi, A. M. Wen, J. F. Edelbrock, J. K. Pokorski, U. Commandeur, G. R. Dubyak and N. F. Steinmetz, Acta Biomaterialia, 2015, 19, 166-179.

42 A. K. Kenworthy, K. Hristova, D. Needham and T. J. McIntosh, Biophysical 
Journal, 1995, 1921-1936.

43 R. Jordan and A. Ulman, J Am Chem Soc, 1998, 120, 243-247.

44 G. K. Lee, N. Maheshri, B. Kaspar and D. V. Schaffer, Biotechnol. Bioeng., 2005, 92, 24-34.

45 M. A. Croyle, N. Chirmule, Y. Zhang and J. M. Wilson, J. Virol., 2001, 75, 47924801.

46 J. L. Perry, K. G. Reuter, M. P. Kai, K. P. Herlihy, S. W. Jones, J. C. Luft, M. Napier, J. E. Bear and J. M. DeSimone, Nano Lett., 2012, 12, 5304-5310.

47 A. S. Pitek, A. M. Wen, S. Shukla and N. F. Steinmetz, Small, 2016, 12, 1758-1769.

48 Z. He, L. Miao, R. Jordan, D. S-Manickam, R. Luxenhofer and A. V. Kabanov, Macromol. Biosci., 2015, 15, 1004-1020. 